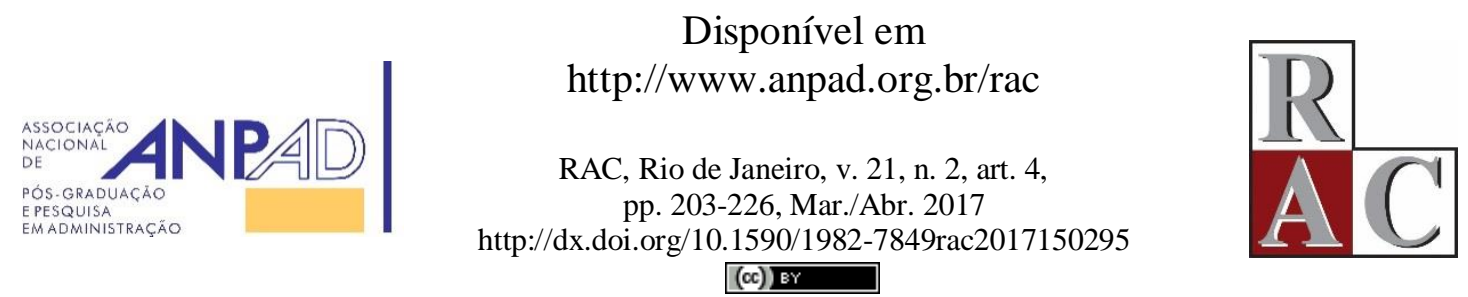

\title{
Diferenças no Composto Varejista de Lojas Físicas e Virtual da Mesma Rede
}

\author{
Retail Mix Differences between Off-line and On-line Stores of the Same Chain
}

Mário Duarte dos Santos Machado1 Sergio Feliciano Crispim ${ }^{1,2}$

Universidade Municipal de São Caetano do Sul ${ }^{1}$ Universidade de São Paulo

Artigo recebido em 24.10.2015. Última versão recebida em 14.06.2016. Aprovado em 18.06.2016. Publicado online em 05.10.2016. 


\title{
Resumo
}

A diversificação dos formatos de loja e a dispersão dos limites entre os canais de varejo - fato movidos pela ampliação do alcance da internet - têm levado varejistas a deixarem de operar um único canal de vendas para tornarem-se multicanais. Diante dessa realidade, o presente estudo visa identificar e analisar as diferenças em componentes do composto de varejo - sortimento, preço, faixas de preços e serviços - em lojas físicas e virtuais de varejistas que operam os dois canais. A pesquisa foi desenvolvida em quatro fases: (a) definição dos varejistas e localização das lojas, seleção dos departamentos e das categorias de produtos; (b) coleta de dados; (c) análise dos dados e identificação das diferenças; (d) realização de entrevistas semiestruturadas com líderes das empresas. A partir de uma amostra com 756 modelos em seis categorias de produtos, constatou-se que o varejo virtual é mais competitivo que o varejo físico em relação ao sortimento (91\% maior), aos preços praticados (de $13 \%$ a $15 \%$ menores), às vantagens de pagamentos (de 3 a 12 vezes sem juros) e à amplitude de faixas de preços. Mantidos esses diferenciais competitivos e garantidas a credibilidade na entrega e a possibilidade de troca ou devolução, o varejo virtual tem uma perspectiva consistente de crescimento proporcionalmente maior do que a do varejo físico.

Palavras-chave: varejo on-line; canais varejistas; sortimento; preço; serviços.

\begin{abstract}
Diversification of store formats and dispersion of boundaries between retail channels - facts arising from the expansion of the scope of Internet - have led many retailers to move from single channel to multichannel operation. With this in view, the present study aims to identify and analyse the differences in retail components - assortment, price, price ranges and services - between physical and virtual stores operating both channels. The research was developed in four phases: (a) definition of retailers and location of stores, selection of departments and product categories; (b) data collection; (c) data analysis and identification of differences; (d) semi-structured interviews with company leaders. A sample of 756 models in six product categories shows that virtual retail is more competitive than physical retail as to assortment (91\% higher), prices(13\% to $15 \%$ lower), more attractive payment terms(3-12 installments without interest) and width of price ranges. If these competitive advantages are kept along with the guarantee of credibility in delivery and possibility of exchange or refund, virtual retail is bound to have a consistent growth perspective proportionally greater than that of physical retail.
\end{abstract}

Key words: on-line retail; retail channels; assortment; price; services. 


\section{Introdução}

Reichheld e Schefter (2000, p. 113) destacam que "os consumidores de hoje têm uma reduzida tolerância à inconsistência e à mediocridade em função da velocidade com que são obtidas as informações de que necessitam". Eles enfatizam que, no varejo antigo, ou anterior ao advento da internet,

a localização das lojas, vendedores com objetivos e metas agressivas de vendas, e a falta de informação para o consumidor protegiam os fornecedores e os varejistas das penalidades de oferecer qualquer coisa que não o melhor produto, com bom sortimento, preço justo e qualidade de serviços. (Reichheld \& Schefter, 2000, p. 113)

Neste contexto, a lealdade do consumidor derivava da grande assimetria de informação que lhe era desfavorável em relação aos fornecedores em geral, e não da possibilidade da melhor escolha. A partir do advento da Internet e do desenvolvimento do e-commerce, a assimetria de informação é significativamente reduzida em favor dos consumidores por meio da maior transparência e da comparabilidade das ofertas, implicando em um aumento generalizado da concorrência e do valor entregue aos clientes (Evans \& Wurster, 2000). Com o crescente aumento da concorrência nos mercados e da ampliação do alcance da internet, vários varejistas estão se movendo da operação comum de um único canal para a operação multicanal, e o canal on-line vem se tornando cada vez mais relevante na formulação das suas estratégias (Rao, Goldsby, \& Iyengar, 2009).

"Para os lojistas, a decisão de preço é um importante componente da estratégia de marketing e exerce uma forte influência sobre os objetivos dos consumidores" (Davidson, Sweeney, \& Stampfl, 1988, p. 404). "Com mais formatos de loja e consequente dispersão dos limites entre os canais, o processo de definição do sortimento também ganha relevância crítica e importância estratégica" (Levy \& Weitz, 2012, p. 316).

Por outro lado, Melis, Campo, Breugelmans e Lamey (2015) em pesquisa recente sobre operações multicanal, reiteram que o sortimento não é apenas um fator crítico devido ao seu efeito direto sobre as decisões de escolha da loja, mas também aumenta a probabilidade dos consumidores revisitarem a loja on-line trazendo impacto positivo na fidelidade do canal em detrimento do canal físico. De forma complementar, Lin e Lekhawipat (2014) argumentam que a satisfação do cliente não só tem um impacto direto na intenção de recompra on-line, mas também tem uma influência indireta no ajuste das expectativas, advindas das incertezas geradas pelo canal on-line.

Já Bratnagar e Syam (2013) apontam que, para algumas linhas de mercadorias, as expectativas de preço, o sortimento de produtos, as condições de pagamento e os serviços oferecidos são importantes para o consumidor na determinação de quais lojas serão visitadas e, consequentemente, na tomada de decisão de compra. É nessa perspectiva sobre a importância do retailing mix na decisão de compra dos consumidores e nas suas potenciais diferenças de composição em lojas físicas e virtuais que se alinha a presente pesquisa. Especificamente identifica-se aqui uma lacuna na literatura, dado haver estudos específicos sobre preço, sortimento ou serviços no varejo on-line e off-line em outros países, mas a ausência de pesquisas que estudam essas variáveis de forma integrada e simultaneamente no varejo online e off-line brasileiro.

Numa perspectiva mais ampla, a presente pesquisa justifica-se e se insere no campo da estratégia empresarial, relacionando-se particularmente à atratividade setorial. Um reconhecido corpo teórico sobre a competição foi desenvolvido em uma vertente denominada organização industrial, que tem como pressuposto fundamental a dependência crítica da estratégia de posicionamento das empresas relativamente às características do setor no qual atuam (Jain \& Haley, 2009). Nesse sentido, Barney e Hesterly (2007), corroborando Porter (1989), propõem que um dos maiores desafios e pressupostos para o desenvolvimento de uma boa estratégia empresarial é a compreensão da atratividade do setor no qual a empresa se insere. Segundo Rappaport (2001), a atratividade setorial - exógena e independente das empresas individualmente - é determinante fundamental do potencial de retorno e de criação de valor 
para os acionistas. A atratividade setorial reflete-se significativamente no crescimento e rentabilidade intrínsecos a um setor.

Na pesquisa que foi realizada, a justificativa teórica situa-se mais especificamente na contribuição para compreender porque a atratividade do setor de e-commerce é significativamente maior do que a atratividade do setor de varejo físico. Parcela da explicação para a maior atratividade - traduzida por crescimento de vendas do e-commerce muito superior ao do comércio físico - está no campo teórico do comportamento do consumidor, ou seja, nos fatores que explicam a maior preferência pelo e-commerce no processo de decisão de compra, que se relaciona à entrega de maior valor comparativamente ao varejo tradicional.

A justificativa teórica para a pesquisa - centrada na compreensão da atratividade setorial - pode se dar, além da perspectiva do comportamento do consumidor, na perspectiva de modelo de negócio, que, segundo Amit e Zott (2012), é um sistema de atividades interconectadas e interdependentes que determina a forma como uma empresa faz negócios com seus parceiros e clientes. Pode ser entendido como um framework que visa definir os principais blocos constitutivos da estratégia, bem como seu alinhamento e consistência. Seguem os principais blocos propostos por Osterwalder e Pigneur (2011) para um modelo de negócio e seu alinhamento à pesquisa que foi realizada. Um primeiro bloco do modelo de negócio diz respeito à proposta de valor, que explicita o escopo de produtos e serviços a ser entregue aos clientes. Ao avaliar as diferenças do retailing mix (sortimento, preço e serviços) entre as mesmas lojas que atuam no varejo virtual e físico - que explicam o comportamento de compras do consumidor, a presente pesquisa conecta-se a esse bloco do modelo de negócio. Esse é o componente do modelo observável pelo mercado, sendo que os outros que o viabilizam ficam relativa ou absolutamente ocultos. Um segundo bloco do modelo de negócio refere-se à segmentação de mercado, ou segmento de mercado que deve ser atendido prioritariamente pelo modelo de negócio. Por um lado, as restrições físicas das lojas tradicionais (número de lojas, área de vendas, reserva imediata de produtos, vendedores etc.) restringem naturalmente o sortimento, e exigem segmentações de mercado também mais delimitadas. Por outro, no varejo on-line, as restrições físicas anteriores são muito menores ou inexistem, possibilitando um processo de segmentação de mercado muito menos delimitado para as lojas que atuam virtualmente do que para as lojas físicas.

Um terceiro bloco do modelo de negócio conceitual é o canal, que define a interface com os consumidores. Na presente pesquisa, é precisamente o canal - virtual ou físico - que deflagra possibilidades muito distintas de organização dos outros blocos do modelo de negócio, explicando as diferenças pesquisadas e identificadas em termos de sortimento, preço e serviço. Os dois componentes operacionais do modelo de negócio - recursos e capacidades - podem ter configurações muito diferentes em operações virtuais e físicas de varejo, que redundam em um sexto bloco do modelo de negócio - estruturas de custos - também diferentes. Embora o varejo virtual implique maiores custos de infraestrutura de TI e de logística, há fortes indicações de que esses adicionais de custos sejam bem menores do que os custos das lojas físicas. As diferentes estruturas de custos possibilitam diferentes modelos de receitas - sétimo bloco do modelo de negócio - que, na presente pesquisa, explicariam os preços (proposta de valor) significativamente menores no comércio eletrônico.

Dadas a lacuna - ou o gap - e as justificativas teóricas já expostas, formulou-se o seguinte problema de pesquisa: quais são as principais diferenças do composto de varejo entre lojas físicas e lojas virtuais de empresas que operam simultaneamente em ambos os canais no mercado brasileiro? $\mathrm{O}$ objetivo da pesquisa é identificar e analisar as diferenças em - sortimento, preço, faixas de preço e serviços - entre os canais físico e virtual de redes que atuam nos dois canais. 


\section{Referencial Teórico}

\section{O varejo multicanal}

O varejo multicanal pode ser definido como a coordenação das operações de ambos os canais, on-line e off-line, através dos quais os clientes e os varejistas interagem (Verhoef, Neslin, \& Vroomem, 2007). Os mesmos autores observam que, enquanto as lojas on-line têm a vantagem de eliminar o deslocamento até a loja física, estas têm a vantagem de oferecer produtos para serem tocados, experimentados, avaliados, adquiridos e levados de imediato. Em função dessas diferenças de atributos, as operações das lojas físicas e das on-line são, por natureza, diferentes. O Apêndice A apresenta atributos das lojas físicas e das virtuais apontados por diversos autores, evidenciando as diferenças entre os dois canais.

No sentido de destacar as operações realizadas por meios eletrônicos, Rosenbloom (2009, p.365) utiliza a expressão canais de marketing eletrônico como sendo o uso da internet para tornar produtos e serviços disponíveis, de tal forma que o mercado-alvo possa comprar e completar a transação de compra por meios eletrônicos interativos.

Berman e Thelen (2004) consideram que uma boa integração multicanal permite que o consumidor examine o produto em um determinado canal, compre em outro e, finalmente, retire-o ou, eventualmente, devolva-o em outro local. Ainda segundo os autores, o varejo multicanal oferece sinergias que podem resultar numa base maior de clientes, em mais rentabilidade e participação de mercado, sendo necessário um planejamento detalhado e o desenvolvimento de uma infraestrutura que possa prover a interação entre os canais.

\section{Sortimento no varejo}

O grau de concorrência entre os varejistas não é somente baseado na diferenciação das mercadorias. O sortimento e a variedade são fatores relevantes de competitividade e diferenciação. Hoch, Bradlow e Wansink (1999) confirmam que os varejistas reconhecem que os consumidores valorizam o sortimento como uma variável importante na tomada de decisão de compra. Levy e Weitz (2012) apresentam a componente sortimento como "o número de itens diferentes em uma categoria de mercadoria, sendo que cada item é denominado como unidade de manutenção de estoque (stock keeping unit - SKU), e variedade como o número de categorias diferentes oferecidas por um varejista" (p. 314). O sortimento deve buscar um equilíbrio entre variedade (número de categorias), profundidade (número de unidades de estoque - SKUs - dentro de uma categoria), e nível de serviço (o número de itens individuais de um determinado $S K U$ ) (Mantrala et al., 2009).

Em última análise, pelo grau de importância dado ao componente sortimento, uma das decisões estratégicas básicas que um varejista deve tomar envolve a determinação do sortimento de produtos a serem oferecidos pelo canal, seja ele físico ou on-line.

\section{Preço e faixas de preço no varejo}

Dentro do composto varejista, um dos componentes mais relevantes e condicionadores da própria tipologia do varejo é o preço.

Do ponto de vista do consumidor, o preço de um produto ou serviço é a variável mais fácil de comparar e, do ponto de vista do varejista, a mais fácil de operacionalizar, portanto, o preço tornase o elemento tático mais utilizado para criar diferenciais competitivos momentâneos ou até mesmo instantâneos, no caso das lojas on-line, visando atrair a atenção dos consumidores (Mattar, 2011, p. 485). 
Por outro lado, (Davidson et al., 1988) destacam que as expectativas de preço de determinados grupos de consumidores podem não ser tão importantes na determinação do comportamento de compra e na preferência da loja. Esses consumidores nem sempre buscam o produto mais barato ou a loja com menor preço. Tal fato ocorre para os produtos pelos quais eles tendem a usar o preço como um indicador substitutivo de qualidade percebida. Além disso, parecem ser mais sensíveis ao conceito de valor, ou seja, o conjunto de benefícios recebidos versus o composto de custos - monetários e não monetários. Toledo, Proença e Mello (2006) afirmam que os consumidores que compram pela internet dispõem de inúmeras facilidades e ferramentas para realizarem pesquisas e obter comparações instantâneas de preços de diferentes fornecedores, sejam eles fabricantes, atacadistas ou varejistas, levando os varejistas que operam em ambos os canais a adotarem políticas de preços diferenciadas para o canal on-line.

Em função de políticas de preços diferentes entre os canais, Underhill (1999) destaca que os varejistas que operam ambos os canais e que competem com varejistas on-line sem loja ou lojas on-line de fornecedores do varejo precisam ficar atentos à precificação no canal on-line, sob pena de solaparem as vendas e os resultados das lojas físicas. Kopalle et al. (2009) destacam que, se as lojas on-line e offline são competidoras no contexto de preço, então se poderia esperar que os gestores de operações multicanal ajustassem os preços para mitigar a concorrência. No entanto, não é essa a realidade de mercado que se observa, reforçada por Takahashi, Aoi, Hirotani e Morikawa (2011), que destacam haver uma clara indicação da interação que os consumidores fazem entre operações de lojas físicas e on-line de varejistas que operam os dois canais simultaneamente, na busca de um menor preço final. Kopalle $e t$ $a l$. (2009) reiteram em estudo que pouco se conhece sobre estratégias de preços, táticas e ações que são, ou poderiam ser, desenvolvidas e implementadas por um varejista que vende on-line.

Uma das ações que visa reduzir a percepção que o consumidor possa ter do preço é indicada por Davidson, Sweeney e Stampfl (1988) e pode ser resumida como sendo a utilização de diversos price points no sortimento de mercadorias com diferenças significativas entre eles. Os price points caracterizam as chamadas faixas de preço. Nesse sentido, a prática de apresentar os preços por meio dessas faixas pode contribuir para reduzir a concorrência por preço entre os canais, dado que o consumidor perde a referência individual do preço.

Dados de pesquisas recentes, realizadas em mercados como: Estados Unidos, França e Índia, indicam que os preços ofertados pelo canal on-line são, em média, 10\% menores quando comparados ao canal físico (E-bit, 2014).

Em função do contexto apresentado, a possibilidade do consumidor comparar os dois canais, online e off-line, ganha destaque no ambiente de varejo e sugere a necessidade dos varejistas desenvolverem operações integradas.

\section{Serviços no varejo}

Lennon e Harris (2001), em estudos voltados para os canais varejistas on-line e off-line, argumentam que ambas as operações caracterizam-se como um conjunto de serviços em que o consumidor tende a optar pelo canal que oferecer o melhor nível de serviços. "O varejo tradicionalmente tem sido classificado como uma indústria de serviços, mas, para muitos varejistas, a preocupação com a qualidade e com os serviços oferecidos pela loja é recente" (McGoldrick, 2002, p. 533). Os serviços no varejo englobam as atividades que apresentam um relacionamento entre o varejista e o consumidor, e podem ser definidos como o conjunto de todas as "características, atividades e informações que aumentam a habilidade do consumidor em reconhecer o valor potencial dos produtos ou serviços oferecidos pelo varejista" (Davidow, 1989 como citado em Parente \& Barki, 2014, p. 258).

McGoldrick (2002, p. 535) destaca que o princípio fundamental das estratégias em serviços varejistas é garantir altos níveis de satisfação do cliente. Venkatesan, Mehta e Ravi (2007) observam que varejistas que oferecem elevados níveis de qualidade dos serviços vendem significativamente mais do que aqueles com baixa qualidade. 
Dessa forma, o componente serviços pode ser o que melhor fixa o perfil da loja na mente do consumidor, pela possibilidade de diferenciação em relação a outros varejistas e, consequentemente, pela entrega de experiências e soluções de consumo mais robustas.

\section{Metodologia}

A presente pesquisa é de natureza descritiva, quantitativa e exploratória, dado que "a amostragem realizada é intencional e não probabilística", de acordo com as definições de Churchill e Peter (1998/2000, p. 126). O seu desenvolvimento foi realizado em quatro fases:

Fase 1 - Definição do ambiente de pesquisa: varejistas com abrangência no mercado nacional, que operam lojas físicas e lojas virtuais e são referências para o consumidor na tomada da decisão de compra, além da localização das lojas, departamentos e categorias de produtos notáveis. A Tabela 1 apresenta as características do ambiente de pesquisa:

Tabela 1

Ambiente de Pesquisa - Varejistas, Localização de Lojas, Departamentos e Categorias

\begin{tabular}{llll}
\hline Lojas Varejistas & Localização das Lojas Físicas & Departamentos & Categorias de Produtos \\
\hline $\begin{array}{l}\text { Fast Shop } \\
\text { Fnac }\end{array}$ & Shopping Paulista e Av. Paulista & Video e Informática & $\begin{array}{l}\text { TVs, Notebooks, Ultrabooks e } \\
\text { Impressoras }\end{array}$ \\
\hline $\begin{array}{l}\text { Magazine Luiza } \\
\text { Casas Bahia }\end{array}$ & Ruas Comerciais do Bairro da & $\begin{array}{l}\text { Video, Informática } \\
\text { Lapa }\end{array}$ & $\begin{array}{l}\text { TVs, Notebooks, Ultrabooks, } \\
\text { Impressoras, Refrigeradores, } \\
\end{array}$ \\
& Bairro do Itaim Bibi & Vídeo, Informática e & $\begin{array}{l}\text { TVs, Notebooks, Ultrabooks, } \\
\text { Micro-Ondas }\end{array}$ \\
\hline Extra & & Eletrodomésticos & $\begin{array}{l}\text { Impressoras, Refrigeradores, } \\
\text { Lavadora / Secadora de Roupa e } \\
\end{array}$ \\
& & & Micro-Ondas \\
\hline Walmart & Shopping Central Plaza, Vila & & \\
& Prudente & & \\
\hline
\end{tabular}

Nota. Fonte: Elaborada pelos autores.

Fase 2 - Definição do roteiro de coleta de dados conforme apresentado na Tabela 2, "com objetivo de estabelecer procedimentos, orientar e garantir a confiabilidade da coleta" (Yin, 2010, p. 106). Apesar de não ser um estudo de caso para a realização da coleta e para o registro dos dados, foi proposto um roteiro que empresta características da proposta de Yin (2010) para estudos de casos. 
Tabela 2

\section{Roteiro para Coleta de Dados}

\begin{tabular}{llll}
\hline Canal & Técnicas de Coleta de Dados & Roteiro para Coleta de Dados \\
\cline { 3 - 4 } & & Produtos & $\begin{array}{l}\text { Serviços ao cliente, meios de } \\
\text { pagamento e comunicação }\end{array}$ \\
\hline Loja física & $\begin{array}{l}\text { Observação dos produtos na } \\
\text { Loja }\end{array}$ & $\begin{array}{l}\text { Coleta dos dados por } \\
\text { departamento, categoria de } \\
\text { produto, marca, modelo, } \\
\text { preço, condições de } \\
\text { pagamento }\end{array}$ & $\begin{array}{l}\text { Entrevistas junto aos } \\
\text { vendedores e ao crediário da } \\
\text { loja }\end{array}$ \\
\cline { 3 - 4 } & $\begin{array}{l}\text { Observação dos produtos no } \text { on-line } \\
\text { Site }\end{array}$ & Leitura direta no site \\
\hline
\end{tabular}

Nota. Fonte: Elaborada pelos autores.

Como condição fundamental da metodologia para uma comparação fidedigna, os dados dos produtos e serviços de cada loja varejista foram coletados no mesmo dia nos dois canais, e todo o processo de coleta se desenvolveu entre os dias 8 e 13 de fevereiro de 2015. No momento da coleta, foram registrados somente os dados dos produtos disponíveis nas lojas de ambos os canais que se enquadravam nas categorias e específicações pré-definidas,

Fase 3 - Consolidação dos dados, realização das análises qualitativas e quantitativas, e identificação das diferenças nos compontentes sortimento, preço e faixas de preço, além dos serviços. $\mathrm{Na}$ busca da variação média entre os valores de preços identificados na pesquisa, foram consideradas todas as variações positivas e negativas entre os preços dos produtos comuns em cada um dos canais.

Fase 4 - Realização de entrevistas semiestruturadas com os diretores de operações dos canais online, visando compreender as estratégias adotadas. Para orientar as entrevistas, foi desenvolvido um roteiro com questões formuladas de acordo com os temas: canais, proposta de valor, atividades-chave, segmentos de clientes, relacionamento com o cliente, parcerias principais, recursos principais, estrutura de custos e fontes de receitas, temas estes baseados nos "nove componentes básicos" do modelo de negócio, propostos por Osterwalder e Pigneur (2011, p. 15) aos quais, chamamos de blocos típicos do modelo de negócio, além de um último tema, proposto pelos autores, sobre a visão de futuro para as operações varejistas. O Apêndice B apresenta os temas propostos, as questões formuladas e a convergência, de forma resumida, das respostas às questões.

\section{Análise dos Resultados}

\section{Análise do componente sortimento}

Foram coletadas, nas seis lojas físicas e nas seis virtuais apresentadas na amostra, informações de 756 modelos diferentes de produtos, distribuídos nas seis categorias previamente definidas, e pôde-se observar que, para todas as categorias, o sortimento e a variedade de modelos no canal on-line é sempre maior do que no canal físico. "No canal on-line, o primeiro pilar é ter um bom sortimento inclusive com a modalidade market place, que é a venda de produtos de outros varejistas no site da loja" (Diretor da Empresa D).

A Tabela 3 apresenta o total de modelos de cada categoria, o número de produtos comuns com repetição e a porcentagem de participação nas lojas físicas e virtuais. 
Tabela 3

Total de Modelos Identificados nas Lojas Físicas e Virtuais - Todas as Categorias

\begin{tabular}{lcccccc}
\hline Categorias & $\begin{array}{c}\text { Total de } \\
\text { Modelos sem } \\
\text { Repetição }\end{array}$ & $\begin{array}{c}\text { Modelos nas } \\
\text { Lojas } \\
\text { Virtuais }\end{array}$ & $\begin{array}{c}\text { Modelos nas } \\
\text { Lojas Físicas }\end{array}$ & $\begin{array}{c}\mathrm{N}^{\circ} \mathrm{de} \\
\text { Modelos } \\
\text { Comuns com } \\
\text { Repetição }\end{array}$ & $\begin{array}{c}\text { Modelos nas } \\
\text { Lojas } \\
\text { Virtuais/Tot. } \\
\text { de Modelos }\end{array}$ & $\begin{array}{c}\text { Modelos nas } \\
\text { Lojas }\end{array}$ \\
$\begin{array}{l}\text { Físicas/Tot. } \\
\text { de Modelos }\end{array}$ \\
\hline TVs & 255 & 220 & 128 & 91 & $86 \%$ & $50 \%$ \\
Note/Ultrabooks & 197 & 177 & 88 & 49 & $90 \%$ & $45 \%$ \\
Refrigeradores & 106 & 103 & 48 & 26 & $97 \%$ & $45 \%$ \\
Impressoras/Multif & 76 & 72 & 28 & 47 & $95 \%$ & $37 \%$ \\
Lava e Lava e Seca & 62 & 60 & 37 & 57 & $97 \%$ & $60 \%$ \\
Micro-Ondas & 60 & 57 & 32 & 31 & $95 \%$ & $53 \%$ \\
\hline Total & 756 & 689 & 361 & 301 & $91 \%$ & $48 \%$ \\
\hline
\end{tabular}

Nota. Fonte: Elaborada pelos autores.

Após análise dos dados, constatou-se que as lojas virtuais disponibilizam, nas categorias pesquisadas, um sortimento maior de modelos. No entanto, a quantidade de modelos comuns entre os canais físico e virtual corresponde a $40 \%$ do total, ou seja, um percentual reduzido, levando-se em conta operações de um mesmo varejista. Em tese, essa tática de oferecer sortimento diferente em cada canal pode ser parte da estratégia varejista de não disponibilizar um número maior de modelos para comparações de preços e, assim, dificultar a negociação do consumidor na busca de condições mais favoráveis entre os canais. No mesmo sentido, pode-se prever que a estratégia é alimentada pelos fornecedores ao oferecerem uma gama extensa de modelos, com diferenças que, na sua maioria, não são percebidas pelo consumidor, desconhecidas das equipes de venda das lojas físicas e pouco exploradas pelo canal on-line.

Também para o varejo físico, os custos de armazenagem, exposição, manuseio e gerenciamento podem ser maiores, além de ampliar o custo do espaço virtual, pela necessidade de divulgar mais opções no site da loja on-line. Mesmo assim, Hoch et al. (1999) confirmam que os varejistas reconhecem que os consumidores valorizam a variedade de sortimento da loja e consideram essa variável importante na tomada de decisão de compra.

\section{Análise dos componentes preço e faixas de preços}

Com base nos modelos comuns às lojas físicas e virtuais de um mesmo varejista, procedeu-se à análise comparativa da variação de preços entre os canais, considerando-se os preços nominais à vista. Foi identificada uma variação média percentual de $-13,3 \%$ nos preços nominais das lojas virtuais em relação às lojas físicas, com base nas comparações de preços de 210 modelos comuns às mesmas, conforme a Tabela 4. Há alguma variação entre as diferenças no nível das categorias, mas, em média, os preços das lojas virtuais são sempre mais baixos. Dado que os produtos comparados nas mesmas cadeias são idênticos e de elevado valor unitário, os ganhos absolutos pela compra nas lojas virtuais podem ser considerados expressivos. No caso de televisores, por exemplo, o preço médio amostrado foi de $\mathrm{R} \$ 4.200,00$, e o ganho médio seria de $-15,4 \%$, ou de $\mathrm{R} \$ 647,00$. Em refrigeradores, o preço médio foi de $\mathrm{R} \$ 2.700,00$, e o ganho médio seria de $-16,8 \%$, ou de $\mathrm{R} \$ 454,00$.

Por meio da Tabela 4, pode-se observar que, em 90\% das comparações de preços, os preços das lojas virtuais são menores que os das lojas físicas, ou seja, há uma distribuição quase que totalmente assimétrica, favorável aos preços das lojas virtuais. 
Para ampliar a robustez da análise das variações médias de preços observadas, adotou-se o teste paramétrico paramétrico $t$ de Student, isto é, segundo Morettin e Bussab (2013, p. 371) "o teste t de Student para observações pareadas (emparelhadas), supondo normalidade, é apropriado". Com base nas médias percentuais de duas amostras, testou-se a hipótese de que elas provêm de universos com mesma média percentual $\mu 1=\mu 2=\mu$. Como os dados são emparelhados, a variável adotada no teste é a média das diferenças percentuais de preços $(\mu \mathrm{d})$ entre os $\mathrm{n}$ pares observados. Testaram-se, assim, as hipóteses $\mathrm{H} 0$ e H1:

H0: $\mu 1-\mu 2=0, \operatorname{logo} \mu \mathrm{d}=0$, e não há diferença de preços entre o canal físico e o virtual.

H1: $\mu 1-\mu 2 \neq 0, \operatorname{logo} \mu \mathrm{d} \neq 0$, e há diferença de preços entre o canal físico e o virtual.

Se $\mid \mathrm{t}$ calculado $\mid<\mathrm{t}$ crítico; $\alpha$, aceita-se $\mathrm{H} 0: \mu \mathrm{d}=0$; caso contrário, rejeita-se $\mathrm{H} 0$ a favor de $\mathrm{H} 1$ : $\mu \mathrm{d} \neq 0$. Adotou-se t crítico; $\alpha$ ao nível de $5 \%$ de significância, dado que a observação dos dados demostrou ser um teste monocaudal. Conforme a tabela 4, em todas as categorias de produtos, o teste leva à rejeição da hipótese $\mathrm{H} 0$ e à aceitação de $\mathrm{H} 1$, levando à conclusão e confirmando os indicadores anteriores de que os preços das lojas virtuais são significativamente inferiores aos das lojas físicas.

Tabela 4

\section{Diferenças de Preços Nominais entre Lojas Virtuais e Físicas}

\begin{tabular}{|c|c|c|c|c|c|c|c|c|}
\hline \multirow[t]{3}{*}{$\begin{array}{l}\text { Categorias de } \\
\text { produtos } \\
\text { pesquisadas }\end{array}$} & \multicolumn{4}{|c|}{$\begin{array}{c}\text { Modelos encontrados nas lojas } \\
\text { pesquisadas (base para a comparação de } \\
\text { preços) }\end{array}$} & \multirow[t]{3}{*}{$\begin{array}{l}\text { Médias das diferenças } \\
\text { de preço entre lojas } \\
\text { virtuais e físicas }\end{array}$} & \multicolumn{3}{|c|}{ Significância das diferenças } \\
\hline & \multirow[t]{2}{*}{ Total } & \multirow[t]{2}{*}{ Virtuais } & \multirow[t]{2}{*}{ Físicas } & \multirow{2}{*}{$\begin{array}{l}\text { Comuns } \\
\text { aos dois } \\
\text { tipos }(n)\end{array}$} & & \multirow{2}{*}{$\begin{array}{l}\text { Proporção de } \\
\text { comparações } \\
\text { virtual/físico } \\
\text { negativas }\end{array}$} & \multicolumn{2}{|c|}{ Teste $\mathrm{t}$ de student } \\
\hline & & & & & & & $\mid \mathrm{t}$ calc $\mid$ & t crítico $\alpha=5 \%$ \\
\hline Refrigeradores & 106 & 103 & 48 & 38 & $-16,8 \%$ & $95 \%$ & 9,157 & 2,027 \\
\hline Micro-ondas & 60 & 57 & 32 & 23 & $-14,8 \%$ & $83 \%$ & 4,997 & 2,074 \\
\hline TVs & 255 & 220 & 128 & 57 & $-15,4 \%$ & $91 \%$ & 9,390 & 2,003 \\
\hline Lava Roupa & 62 & 60 & 37 & 30 & $-14,1 \%$ & $93 \%$ & 8,336 & 2,045 \\
\hline Note/Ultrabooks & 197 & 177 & 88 & 45 & $-8,9 \%$ & $87 \%$ & 5,880 & 2,016 \\
\hline Impress./Multif. & 76 & 72 & 28 & 17 & $-6,0 \%$ & $82 \%$ & 2,245 & 2,120 \\
\hline Total & 756 & 689 & 361 & 210 & $-13,3 \%$ & $90 \%$ & 16,449 & 1,960 \\
\hline
\end{tabular}

Nota. Fonte: Elaborada pelos autores.

Aprofundando a análise das diferenças de preços, foram considerados os prazos de pagamento e o valor do dinheiro no tempo, que são importantes fatores na tomada de decisão de compra de produtos de elevado valor unitário, e compra comparada. Foram deflacionados somente os preços à vista que poderiam ser pagos em parcelas iguais sem juros (SJ), conforme descrito nos anúncios das lojas. "as condições de mercado no segmento on-line exigem que ofereçamos aos nossos clientes, principalmente em compras de alto valor agregado, prazos de pagamento de 10 a 12 vezes sem juros" (Diretor da Empresa B). As lojas que oferecem valores à vista e parcelas a prazo com juros (CJ) não tiveram seus preços deflacionados, logo não foram consideradas na análise. A Tabela 5 apresenta o número de parcelas e as condições com juros (CJ) e sem juros (SJ) em cada um dos canais. 
Tabela 5

Resumo das Condições de Pagamento Oferecidas pelas Lojas Físicas e Virtuais

\begin{tabular}{|c|c|c|c|c|c|c|c|c|c|c|c|}
\hline Extra & \multicolumn{3}{|c|}{ Walmart } & \multicolumn{2}{|c|}{ Mag. Luiza } & \multicolumn{2}{|c|}{ Casas Bahia } & \multicolumn{2}{|l|}{ Fnac } & \multicolumn{2}{|c|}{ Fast Shop } \\
\hline \multicolumn{12}{|c|}{ Tipo de Loja / Prazos e Condições de Pagamento } \\
\hline Física & Virtual & Física & Virtual & Física & Virtual & Física & Virtual & Física & Virtual & Física & Virtual \\
\hline $12 \mathrm{X} \mathrm{SJ}^{\mathrm{a}}$ & 10X SJ & $24 \mathrm{X} \mathrm{CJ}$ & 10X SJ & $16 \mathrm{X} \mathrm{CJ}$ & $12 \mathrm{X} \mathrm{CJ}$ & $18 \mathrm{X}$ CJ & 10X SJ & $3 \mathrm{X} \mathrm{SJ}$ & $10 \mathrm{X} \mathrm{SJ}$ & $10 \mathrm{X} \mathrm{CJ}$ & $6 \mathrm{X} \mathrm{CJ}$ \\
\hline
\end{tabular}

Nota. Fonte: Elaborada pelos autores.

a As abreviações SJ e CJ têm o significado de sem juros e com juros, respectivamente.

Para as lojas que oferecem prazos de pagamento sem juros (SJ), os valores das parcelas foram corrigidos para valor presente, considerando-se o número de períodos igual ao número de parcelas. A taxa de remuneração da poupança no ano de 2014 foi de 7,02\%. Essa taxa foi considerada como custo de oportunidade do consumidor e serviu de base para o cálculo da taxa mensal. Dado o exposto, foi identificada, conforme a Tabela 6 , uma variação média percentual de $-14,9 \%$ nos preços deflacionados das lojas virtuais em relação às lojas físicas, com base nas comparações de preços de 156 modelos comuns às mesmas. Nessa condição, a competitividade de preço das lojas virtuais é ainda maior do que quando considerados os preços não deflacionados. A proporção de comparações de preços favoráveis às lojas virtuais de $88 \%$ é substancialmente elevada, como no caso dos preços nominais, e os testes t levam à rejeição da hipótese $\mathrm{H} 0$ em quase todas as categorias, com exceção de impressoras/multifuncionais, na qual a amostra de comparações de preços deflacionados ficou reduzida a apenas 13 observações.

Tabela 6

\section{Diferenças de Preços Deflacionados entre Lojas Virtuais e Físicas}

\begin{tabular}{|c|c|c|c|c|c|c|c|c|}
\hline \multirow[t]{3}{*}{$\begin{array}{l}\text { Categorias de } \\
\text { Produtos } \\
\text { Pesquisadas }\end{array}$} & \multicolumn{4}{|c|}{$\begin{array}{l}\text { Modelos encontrados nas lojas } \\
\text { pesquisadas (base para a comparação de } \\
\text { preços) }\end{array}$} & \multirow{3}{*}{$\begin{array}{c}\text { Médias das diferenças de } \\
\text { preço entre lojas virtuais } \\
\text { e físicas }\end{array}$} & \multicolumn{3}{|c|}{ Significância das diferenças } \\
\hline & \multirow[t]{2}{*}{ Total } & \multirow[t]{2}{*}{ Virtuais } & \multirow[t]{2}{*}{ Físicas } & \multirow{2}{*}{$\begin{array}{l}\text { Comuns } \\
\text { aos dois } \\
\text { tipos }(n)\end{array}$} & & \multirow{2}{*}{$\begin{array}{l}\text { Proporção de } \\
\text { comparações } \\
\text { virtual/físico } \\
\text { negativas }\end{array}$} & \multicolumn{2}{|c|}{ Teste $t$ de student } \\
\hline & & & & & & & $\mid \mathrm{t}$ calc $\mid$ & t crítico $\alpha=5 \%$ \\
\hline Refrigeradores & 106 & 103 & 48 & 27 & $-17,3 \%$ & $89 \%$ & 6,126 & 2,056 \\
\hline Micro-ondas & 60 & 57 & 32 & 19 & $-15,1 \%$ & $79 \%$ & 4,174 & 2,101 \\
\hline TVs & 255 & 220 & 128 & 46 & $-18,4 \%$ & $93 \%$ & 9,455 & 2,015 \\
\hline Lava Roupa & 62 & 60 & 37 & 21 & $-13,2 \%$ & $95 \%$ & 5,659 & 2,086 \\
\hline Note/Ultrabooks & 197 & 177 & 88 & 30 & $-12,3 \%$ & $90 \%$ & 5,562 & 2,045 \\
\hline Impress./Multif. & 76 & 72 & 28 & 13 & $-6,2 \%$ & $69 \%$ & 2,006 & 2,179 \\
\hline Total & 756 & 689 & 361 & 156 & $-14,9 \%$ & $88 \%$ & 14,108 & 1,960 \\
\hline
\end{tabular}

Nota. Fonte: Elaborada pelos autores.

Bratnagar e Syam (2013) observam que, para atender às expectativas dos clientes, as lojas oferecem, dentro das categorias, uma distribuição de ofertas de modelos por faixas de preços. Uma análise comparativa foi realizada na categoria TVs, com 128 modelos nas lojas físicas e 220 nas lojas virtuais, observando as repetições. Foram obtidas treze faixas, com grande variação de preços entre elas. A Tabela 7 apresenta os resultados para as lojas físicas. 
Tabela 7

Análise Horizontal das Faixas de Preços - Lojas Físicas - Categoria TVs

\begin{tabular}{|c|c|c|c|c|c|c|c|c|}
\hline \multirow{2}{*}{$\begin{array}{l}\text { Faixas de preços valores } \\
\text { em R\$ }\end{array}$} & \multirow{2}{*}{$\begin{array}{l}\text { Modelos com } \\
\text { repetiçã̃o }\end{array}$} & \multicolumn{7}{|c|}{ Participação da loja em cada faixa de preços } \\
\hline & & Extra & Walmart & Luiza & Bahia & Fnac & Fast & \\
\hline de 269,00 a 999,00 & 17 & $11,8 \%$ & $5,9 \%$ & $41,2 \%$ & $29,4 \%$ & $11,8 \%$ & & $100,0 \%$ \\
\hline de $1.000,00$ a $1.999,00$ & 85 & $28,2 \%$ & $16,5 \%$ & $21,2 \%$ & $23,5 \%$ & $3,5 \%$ & $7,1 \%$ & $100,0 \%$ \\
\hline de $2.000,00$ a $2.999,00$ & 29 & $20,7 \%$ & $10,3 \%$ & $13,8 \%$ & $13,8 \%$ & $27,6 \%$ & $13,8 \%$ & $100,0 \%$ \\
\hline de $3.000,00$ a $3.999,00$ & 14 & $21,4 \%$ & $7,1 \%$ & & $7,1 \%$ & $42,9 \%$ & $21,4 \%$ & $100,0 \%$ \\
\hline de $4.000,00$ a $4.999,00$ & 7 & $14,3 \%$ & $14,3 \%$ & $14,3 \%$ & & $42,9 \%$ & $14,3 \%$ & $100,0 \%$ \\
\hline de $5.000,00$ a $5.999,00$ & 5 & $40,0 \%$ & & & & $60,0 \%$ & & $100,0 \%$ \\
\hline de $6.000,00$ a $6.999,00$ & 3 & & & & & $66,7 \%$ & $33,3 \%$ & $100,0 \%$ \\
\hline de $7.000,00$ a $7.999,00$ & 8 & $12,5 \%$ & & $12,5 \%$ & & $37,5 \%$ & $37,5 \%$ & $100,0 \%$ \\
\hline de $8.000,00$ a $8.999,00$ & 4 & & & & & $75,0 \%$ & $25,0 \%$ & $100,0 \%$ \\
\hline de $9.000,00$ a $9.999,00$ & 5 & $20,0 \%$ & & & & $60,0 \%$ & $20,0 \%$ & $100,0 \%$ \\
\hline de $10.000,00$ a $17.999,00$ & 7 & & & & & $71,4 \%$ & $28,6 \%$ & $100,0 \%$ \\
\hline de $18.000,00$ a $33.999,00$ & 2 & & & & & & $100,0 \%$ & $100,0 \%$ \\
\hline de $34.000,00$ a $450.999,00$ & 2 & & & & & & $100,0 \%$ & $100,0 \%$ \\
\hline Total de modelos & 188 & & & & & & & \\
\hline
\end{tabular}

Nota. Fonte: Elaborada pelos autores.

Observa-se uma concentração de modelos nas faixas de preços chamadas de entrada. Essa disponibilidade de produtos mais econômicos nas lojas físicas permite ao cliente selecionar e levar o modelo escolhido na hora, com pagamento à vista ou mesmo financiado. Constata-se, também, que os modelos das faixas de preços mais altas são oferecidos somente por um dos varejistas, o que pode demonstrar o objetivo de apresentar a loja física como um ambiente de experimentação e inovação tecnológica e, por conseguinte, despertar na mente do cliente uma imagem de vanguarda para a rede, independente do canal de compra.

A Tabela 8 apresenta a análise horizontal das faixas de preços na categoria TVs para as lojas virtuais. No canal on-line, todas as lojas oferecem modelos em cada uma das faixas de preços, mas as de entrada continuam sendo as de maior variedade. Dois pontos se destacam para o canal on-line: sortimento maior por faixas e mais opções em faixas de preços altos. 
Tabela 8

Análise Horizontal das Faixas de Preços - Lojas Virtuais - Categoria TVs

\begin{tabular}{|c|c|c|c|c|c|c|c|c|}
\hline \multirow{2}{*}{$\begin{array}{l}\text { Faixas de Preços valores } \\
\text { em R } \$\end{array}$} & \multirow{2}{*}{$\begin{array}{l}\text { Modelos com } \\
\text { repetição }\end{array}$} & \multicolumn{7}{|c|}{ Participação da Loja em cada Faixa de Preços } \\
\hline & & Extra & Walmart & Luiza & Bahia & Fnac & Fast & \\
\hline de 269,00 a 999,00 & 65 & $26,2 \%$ & $23,1 \%$ & $15,4 \%$ & $32,3 \%$ & $3,1 \%$ & & $100,0 \%$ \\
\hline de $1.000,00$ a $1.999,00$ & 132 & $25,8 \%$ & $22,0 \%$ & $14,4 \%$ & $25,8 \%$ & $3,8 \%$ & $8,3 \%$ & $100,0 \%$ \\
\hline de $2.000,00$ a $2.999,00$ & 72 & $16,7 \%$ & $25,0 \%$ & $13,9 \%$ & $30,6 \%$ & $4,2 \%$ & $9,7 \%$ & $100,0 \%$ \\
\hline de $3.000,00$ a $3.999,00$ & 49 & $18,4 \%$ & $22,4 \%$ & $12,2 \%$ & $22,4 \%$ & $10,2 \%$ & $14,3 \%$ & $100,0 \%$ \\
\hline de $4.000,00$ a $4.999,00$ & 52 & $15,4 \%$ & $23,1 \%$ & $21,2 \%$ & $19,2 \%$ & $7,7 \%$ & $13,5 \%$ & $100,0 \%$ \\
\hline de $5.000,00$ a $5.999,00$ & 25 & $12,0 \%$ & $32,0 \%$ & $12,0 \%$ & $28,0 \%$ & $12,0 \%$ & $4,0 \%$ & $100,0 \%$ \\
\hline de $6.000,00$ a $6.999,00$ & 13 & $30,8 \%$ & $23,1 \%$ & & $15,4 \%$ & $15,4 \%$ & $15,4 \%$ & $100,0 \%$ \\
\hline de $7.000,00$ a $7.999,00$ & 11 & $18,2 \%$ & $27,3 \%$ & $18,2 \%$ & $9,1 \%$ & $9,1 \%$ & $18,2 \%$ & $100,0 \%$ \\
\hline de $8.000,00$ a $8.999,00$ & 14 & $7,1 \%$ & $21,4 \%$ & $35,7 \%$ & $7,1 \%$ & $14,3 \%$ & $14,3 \%$ & $100,0 \%$ \\
\hline de $9.000,00$ a $9.999,00$ & 13 & $7,7 \%$ & $15,4 \%$ & $7,7 \%$ & $15,4 \%$ & & $53,8 \%$ & $100,0 \%$ \\
\hline de $10.000,00$ a $17.999,00$ & 18 & $5,6 \%$ & $22,2 \%$ & $11,1 \%$ & $22,2 \%$ & $16,7 \%$ & $22,2 \%$ & $100,0 \%$ \\
\hline de $18.000,00$ a $33.999,00$ & 13 & $15,4 \%$ & $30,8 \%$ & $7,7 \%$ & $23,1 \%$ & & $23,1 \%$ & $100,0 \%$ \\
\hline de $34.000,00$ a $450.999,00$ & 9 & $11,1 \%$ & $11,1 \%$ & & $11,1 \%$ & $11,1 \%$ & $55,6 \%$ & $100,0 \%$ \\
\hline Total de modelos & 486 & & & & & & & \\
\hline
\end{tabular}

Nota. Fonte: Elaborada pelos autores.

A Tabela 9 apresenta a análise vertical das faixas de preços na categoria TVs nas lojas físicas. Observa-se, mais uma vez, um sortimento maior de modelos nas faixas iniciais.

Tabela 9

\section{Análise Vertical das Faixas de Preços - Lojas Físicas - Categoria TVs}

\begin{tabular}{|c|c|c|c|c|c|c|c|}
\hline \multirow{2}{*}{$\begin{array}{l}\text { Faixas de Preços valores em } \\
\mathrm{R} \$\end{array}$} & \multirow{2}{*}{$\begin{array}{l}\text { Modelos com } \\
\text { Repetição }\end{array}$} & \multicolumn{6}{|c|}{ Perfil da Loja por Faixas de Preços } \\
\hline & & Extra & Walmart & Luiza & Bahia & Fnac & Fast \\
\hline de 269,00 a 999,00 & 17 & $5,0 \%$ & $5,0 \%$ & $22,6 \%$ & $16,7 \%$ & $4,9 \%$ & \\
\hline de $1.000,00$ a $1.999,00$ & 85 & $60,0 \%$ & $70,0 \%$ & $58,1 \%$ & $66,7 \%$ & $7,3 \%$ & $23,1 \%$ \\
\hline de $2.000,00$ a $2.999,00$ & 29 & $15,0 \%$ & $15,0 \%$ & $12,9 \%$ & $13,3 \%$ & $19,5 \%$ & $15,4 \%$ \\
\hline de $3.000,00$ a $3.999,00$ & 14 & $7,5 \%$ & $5,0 \%$ & & $3,3 \%$ & $14,6 \%$ & $11,5 \%$ \\
\hline de $4.000,00$ a $4.999,00$ & 7 & $2,5 \%$ & $5,0 \%$ & $3,2 \%$ & & $7,3 \%$ & $3,8 \%$ \\
\hline de $5.000,00$ a $5.999,00$ & 5 & $5,0 \%$ & & & & $7,3 \%$ & \\
\hline de $6.000,00$ a $6.999,00$ & 3 & & & & & $4,9 \%$ & $3,8 \%$ \\
\hline de $7.000,00$ a $7.999,00$ & 8 & $2,5 \%$ & & $3,2 \%$ & & $7,3 \%$ & $11,5 \%$ \\
\hline
\end{tabular}




\section{Tabela 9 (continuação)}

\begin{tabular}{|c|c|c|c|c|c|c|c|}
\hline \multirow{2}{*}{$\begin{array}{l}\text { Faixas de Preços valores em } \\
\mathrm{R} \$\end{array}$} & \multirow{2}{*}{$\begin{array}{l}\text { Modelos com } \\
\text { Repetição }\end{array}$} & \multicolumn{6}{|c|}{ Perfil da Loja por Faixas de Preços } \\
\hline & & Extra & Walmart & Luiza & Bahia & Fnac & Fast \\
\hline de $8.000,00$ a $8.999,00$ & 4 & & & & & $7,3 \%$ & $3,8 \%$ \\
\hline de $9.000,00$ a $9.999,00$ & 5 & $2,5 \%$ & & & & $7,3 \%$ & $3,8 \%$ \\
\hline de $10.000,00$ a $17.999,00$ & 7 & & & & & $12,2 \%$ & $7,7 \%$ \\
\hline de $18.000,00$ a $33.999,00$ & 2 & & & & & & $7,7 \%$ \\
\hline de $34.000,00$ a $450.999,00$ & 2 & & & & & & $7,7 \%$ \\
\hline Participação Consolidada & 188 & $100 \%$ & $100 \%$ & $100 \%$ & $100 \%$ & $100 \%$ & $100 \%$ \\
\hline Total de Modelos p/ Loja & & 40 & 20 & 31 & 30 & 41 & 26 \\
\hline
\end{tabular}

Nota. Fonte: Elaborada pelos autores.

Por outro lado, constata-se que dois dos varejistas oferecem um mix de modelos mais distribuídos pelas faixas, o que mais uma vez pode confirmar o conceito de busca da imagem de vanguarda tecnológica já apresentada na análise horizontal.

A Tabela 10 dá destaque à análise vertical das faixas de preço nas lojas virtuais. Diferente do que foi constatado na Tabela 9, a Tabela 10 demonstra que o mix de cada uma das lojas on-line disponibiliza modelos em praticamente todas as faixas de preços, o que permite ao consumidor mais acostumado às compras on-line a comparação entre diversos modelos com diferentes atributos e preços. A condição de comparar preços através das faixas de preço pode confirmar a indicação dada por Davidson et al. (1988), de que uma das ações que visa reduzir a percepção que o consumidor possa ter do preço é a utilização de diversos price points (ou faixas de preço), com diferenças claramente distintas entre eles, o que pode contribuir para reduzir a concorrência por preço entre os canais.

Tabela 10

Análise Vertical das Faixas de Preços - Lojas Virtuais - Categoria TVs

\begin{tabular}{lcllllll}
\hline \multirow{2}{*}{$\begin{array}{l}\text { Faixas de Preços valores em } \\
\text { R }\end{array}$} & $\begin{array}{l}\text { Modelos com } \\
\text { Repetição }\end{array}$ & \multicolumn{7}{l}{ Perfil da Loja por Faixas de Preços } \\
\cline { 3 - 8 } & & Extra & Walmart & Luiza & Bahia & Fnac & Fast \\
\hline de 269,00 a 999,00 & 65 & $17,9 \%$ & $13,3 \%$ & $14,3 \%$ & $17,6 \%$ & $6,5 \%$ & \\
\hline de $1.000,00$ a $1.999,00$ & 132 & $35,8 \%$ & $25,7 \%$ & $27,1 \%$ & $28,6 \%$ & $16,1 \%$ & $19,0 \%$ \\
de $2.000,00$ a $2.999,00$ & 72 & $12,6 \%$ & $15,9 \%$ & $14,3 \%$ & $18,5 \%$ & $9,7 \%$ & $12,1 \%$ \\
\hline de $3.000,00$ a $3.999,00$ & 49 & $9,5 \%$ & $9,7 \%$ & $8,6 \%$ & $9,2 \%$ & $16,1 \%$ & $12,1 \%$ \\
de $4.000,00$ a $4.999,00$ & 52 & $8,4 \%$ & $10,6 \%$ & $15,7 \%$ & $8,4 \%$ & $12,9 \%$ & $12,1 \%$ \\
\hline de $5.000,00$ a $5.999,00$ & 25 & $3,2 \%$ & $7,1 \%$ & $4,3 \%$ & $5,9 \%$ & $9,7 \%$ & $1,7 \%$ \\
de $6.000,00$ a $6.999,00$ & 13 & $4,2 \%$ & $2,7 \%$ & & $1,7 \%$ & $6,5 \%$ & $3,4 \%$ \\
\hline de $7.000,00$ a $7.999,00$ & 11 & $2,1 \%$ & $2,7 \%$ & $2,9 \%$ & $0,8 \%$ & $3,2 \%$ & $3,4 \%$ \\
de $8.000,00$ a $8.999,00$ & 14 & $1,1 \%$ & $2,7 \%$ & $7,1 \%$ & $0,8 \%$ & $6,5 \%$ & $3,4 \%$ \\
de $9.000,00$ a $9.999,00$ & 13 & $1,1 \%$ & $1,8 \%$ & $1,4 \%$ & $1,7 \%$ & & $12,1 \%$ \\
\hline
\end{tabular}




\section{Tabela 10 (continuação)}

\begin{tabular}{lcclllll}
\hline \multirow{2}{*}{$\begin{array}{l}\text { Faixas de Preços valores em } \\
\text { R }\end{array}$} & $\begin{array}{l}\text { Modelos com } \\
\text { Repetição }\end{array}$ & \multicolumn{7}{l}{ Perfil da Loja por Faixas de Preços } \\
\cline { 3 - 8 } & & Extra & Walmart & Luiza & Bahia & Fnac & Fast \\
\hline de $10.000,00$ a $17.999,00$ & 18 & $1,1 \%$ & $3,5 \%$ & $2,9 \%$ & $3,4 \%$ & $9,7 \%$ & $6,9 \%$ \\
\hline de $18.000,00$ a $33.999,00$ & 13 & $2,1 \%$ & $3,5 \%$ & $1,4 \%$ & $2,5 \%$ & & $5,2 \%$ \\
de 34.000,00 a 450.999,00 & 9 & $1,1 \%$ & $0,9 \%$ & & $0,8 \%$ & $3,2 \%$ & $8,6 \%$ \\
Participação Consolidada & 486 & $100,0 \%$ & $100,0 \%$ & $100,0 \%$ & $100,0 \%$ & $100,0 \%$ & $100,0 \%$ \\
\hline Total de Modelos p/ Loja & & 95 & 113 & 70 & 119 & 31 & 58 \\
\hline
\end{tabular}

Nota. Fonte: Elaborada pelos autores.

\section{Análise do componente serviços}

A Tabela 11 compara os serviços oferecidos aos clientes pelas lojas físicas e virtuais de cada varejista. Exceto pelos serviços oferecidos por três lojas on-line (Extra.com, Bahia.com e Fnac.com), os quais permitem ao cliente comprar na loja on-line e retirar na loja física, os demais serviços oferecidos pelas lojas físicas e on-line da mesma rede são semelhantes.

Tabela 11

\section{Serviços ao Cliente - Lojas Físicas e Lojas Virtuais}

\begin{tabular}{|c|c|c|c|c|c|c|c|c|c|c|c|c|}
\hline \multirow[t]{3}{*}{ Serviços } & \multicolumn{2}{|c|}{ Extra } & \multicolumn{2}{|c|}{ Walmart } & \multicolumn{2}{|c|}{ M. Luiza } & \multicolumn{2}{|c|}{ C. Bahia } & \multicolumn{2}{|c|}{ Fnac } & \multicolumn{2}{|c|}{ F. Shop } \\
\hline & \multicolumn{12}{|c|}{ Tipo de Loja } \\
\hline & $\mathrm{F}^{\mathrm{a}}$ & $\mathrm{V}$ & $\mathrm{F}$ & $\mathrm{V}$ & $\mathrm{F}$ & $\mathrm{V}$ & $\mathrm{F}$ & $\mathrm{V}$ & $\mathrm{F}$ & $\mathrm{V}$ & $\mathrm{F}$ & V \\
\hline Garantia Estendida & $\mathrm{x}$ & $\mathrm{x}$ & $\mathrm{x}$ & $\mathrm{x}$ & $\mathrm{x}$ & $\mathrm{x}$ & $\mathrm{x}$ & $\mathrm{x}$ & $\mathrm{x}$ & $\mathrm{x}$ & $\mathrm{x}$ & $\mathrm{x}$ \\
\hline Seguro Roubo/Furto & & & & & & & & & $\mathrm{x}$ & $\mathrm{x}$ & $\mathrm{x}$ & $\mathrm{x}$ \\
\hline Instalação/Orientação/Suporte & $\mathrm{x}$ & $\mathrm{x}$ & & & & & $\mathrm{x}$ & $\mathrm{x}$ & & & $\mathrm{x}$ & $\mathrm{x}$ \\
\hline Lista de Casamento & $\mathrm{x}$ & $\mathrm{x}$ & $\mathrm{x}$ & $\mathrm{x}$ & & & $\mathrm{x}$ & $\mathrm{x}$ & $\mathrm{x}$ & $\mathrm{x}$ & $\mathrm{x}$ & $\mathrm{X}$ \\
\hline Vale-Presente & $\mathrm{x}$ & $\mathrm{x}$ & $\mathrm{x}$ & $\mathrm{x}$ & $\mathrm{x}$ & $\mathrm{x}$ & $\mathrm{x}$ & $\mathrm{x}$ & $\mathrm{x}$ & $\mathrm{x}$ & & \\
\hline $\begin{array}{l}\text { Frete Grátis } \\
\text { Promocional/Eventual }\end{array}$ & $\mathrm{x}$ & $\mathrm{x}$ & $\mathrm{x}$ & $\mathrm{x}$ & $\mathrm{x}$ & $\mathrm{x}$ & $\mathrm{x}$ & $\mathrm{x}$ & $\mathrm{x}$ & $\mathrm{x}$ & $\mathrm{x}$ & $\mathrm{x}$ \\
\hline Entrega Programada & $\mathrm{x}$ & $\mathrm{x}$ & $\mathrm{x}$ & $\mathrm{x}$ & & & $\mathrm{x}$ & $\mathrm{x}$ & $\mathrm{x}$ & $\mathrm{x}$ & & \\
\hline Acompanhamento do Pedido & $\mathrm{x}$ & $\mathrm{x}$ & $\mathrm{x}$ & $\mathrm{x}$ & $\mathrm{x}$ & $\mathrm{x}$ & $\mathrm{x}$ & $\mathrm{x}$ & $\mathrm{x}$ & $\mathrm{x}$ & $\mathrm{x}$ & $\mathrm{x}$ \\
\hline Compra on-line/Retira na loja & & $\mathrm{x}$ & & & & & & $\mathrm{x}$ & & $\mathrm{x}$ & & \\
\hline Política de Trocas/Devolução & $\mathrm{x}$ & $\mathrm{x}$ & $\mathrm{x}$ & $\mathrm{x}$ & $\mathrm{x}$ & $\mathrm{x}$ & $\mathrm{x}$ & $\mathrm{x}$ & $\mathrm{x}$ & $\mathrm{x}$ & $\mathrm{x}$ & $\mathrm{x}$ \\
\hline Total de Serviços Disponíveis & 8 & 9 & 7 & 7 & 5 & 5 & 8 & 9 & 8 & 9 & 7 & 7 \\
\hline
\end{tabular}

Nota. Fonte: Elaborada pelos autores.

${ }^{a}$ As letra F e V apresentadas na tabela indicam, respectivamente, as palavras Física e Virtual.

Essa constatação sobre os serviços ao cliente pode, por um lado, sinalizar uma convergência entre as operações, visando minimizar uma possível percepção que o cliente possa ter de diferenças no atendimento em cada um dos canais e, assim, sentir-se à vontade para exercer a compra no canal que lhe for mais conveniente no momento de sua decisão. Por outro lado, a padronização dos serviços entre os canais pode permitir a redução de custos de um mesmo serviço, para o varejista. 
A Tabela 12 apresenta os serviços relacionados aos meios de pagamento, com destaque para a utilização do cartão de débito nas lojas físicas em detrimento das lojas virtuais da mesma rede, sendo que a disponibilidade de pagamento eletrônico via prestador de serviços do tipo pay pal, ocorre em apenas duas lojas (Extra.com e Bahia.com) e o pagamento por transferência eletrônica simples é oferecido somente pela loja Fnac.com.

Tabela 12

\section{Serviços - Meios de Pagamento - Lojas Físicas e Virtuais}

\begin{tabular}{|c|c|c|c|c|c|c|c|c|c|c|c|c|}
\hline \multirow[t]{3}{*}{ Meios de Pagamento } & \multicolumn{2}{|c|}{ Extra } & \multicolumn{2}{|c|}{ Walmart } & \multicolumn{2}{|c|}{ M. Luiza } & \multicolumn{2}{|c|}{ C. Bahia } & \multicolumn{2}{|c|}{ Fnac } & \multicolumn{2}{|c|}{ F. Shop } \\
\hline & \multicolumn{12}{|c|}{ Tipo de Loja } \\
\hline & $\mathrm{F}^{\mathrm{a}}$ & $\mathrm{V}$ & $\mathrm{F}$ & $\mathrm{V}$ & $\mathrm{F}$ & $\mathrm{V}$ & $\mathrm{F}$ & $\mathrm{V}$ & $\mathrm{F}$ & $\mathrm{V}$ & $\mathrm{F}$ & $\mathrm{V}$ \\
\hline Cartão de Débito & $\mathrm{x}$ & $\mathrm{x}$ & $\mathrm{x}$ & & $\mathrm{x}$ & & $\mathrm{x}$ & $\mathrm{x}$ & $\mathrm{x}$ & & $\mathrm{x}$ & \\
\hline Cartão de Crédito Bandeiras & $\mathrm{x}$ & $\mathrm{x}$ & $\mathrm{x}$ & $\mathrm{x}$ & $\mathrm{x}$ & $\mathrm{x}$ & $\mathrm{x}$ & $\mathrm{x}$ & $\mathrm{x}$ & $\mathrm{x}$ & $\mathrm{x}$ & $\mathrm{x}$ \\
\hline Cartão de Crédito on-brand & $\mathrm{x}$ & $\mathrm{x}$ & $\mathrm{x}$ & $\mathrm{x}$ & $\mathrm{x}$ & $\mathrm{x}$ & $\mathrm{x}$ & $\mathrm{x}$ & $\mathrm{x}$ & $\mathrm{x}$ & & \\
\hline Boleto Bancário & & $\mathrm{x}$ & & $\mathrm{x}$ & & $\mathrm{x}$ & & $\mathrm{x}$ & & $\mathrm{x}$ & & $\mathrm{x}$ \\
\hline Carnê & & & $\mathrm{x}$ & & $\mathrm{x}$ & & $\mathrm{x}$ & & & & & \\
\hline Dinheiro & $\mathrm{x}$ & & $\mathrm{x}$ & & $\mathrm{x}$ & & $\mathrm{x}$ & & $\mathrm{x}$ & & $\mathrm{x}$ & \\
\hline Transferência Eletrônica & & & & & & & & & & $\mathrm{x}$ & & \\
\hline Pay Pal ou similar & & $\mathrm{x}$ & & & & & & $\mathrm{x}$ & & & & \\
\hline Total de Meios de Pagamento & 4 & 5 & 5 & 3 & 5 & 3 & 5 & 5 & 4 & 4 & 3 & 2 \\
\hline
\end{tabular}

Nota. Fonte: Elaborada pelos autores.

${ }^{a}$ As letra F e V apresentadas na tabela indicam respectivamente as palavras Física e Virtual.

O aspecto mais importante a ser considerado é o de que a grande maioria das lojas utiliza o cartão de crédito com a própria bandeira da loja (on-brand). Essa modalidade de cartão claramente é oferecida pelas áreas de marketing como diferencial a fim de gerar vantagens adicionais para aqueles clientes fiéis à rede, além de cativar novos clientes.

A Tabela 13 destaca os meios de comunicação com os clientes oferecidos pelos dois canais. Constata-se que as opções de comunicação disponibilizadas pelo canal on-line são mais diversificadas do que aquelas oferecidas pelas lojas físicas.

"Temos diversos canais de comunicação e obtenção de feedback, realizamos pesquisas internas com os clientes através do call center, pesquisas de mercado que avaliam um grupo de variáveis, como layout do site, preço, qualidade da entrega, comparações com concorrentes, dentre outras" (Diretor da Empresa B).

O fato do canal on-line disponibilizar um número maior de meios de comunicação entre o cliente e o site pode ser justificado pela necessidade de mitigar os efeitos da característica impessoal da compra. Sendo assim, as lojas on-line buscam utilizar uma série de ferramentas de comunicação com o cliente, no intuito de garantir uma boa experiência antes, durante e depois da compra, além de mantê-lo assistido ao longo de todo o processo. 
Tabela 13

\section{Serviços - Meios de Comunicação com o Cliente - Lojas Físicas e Virtuais}

\begin{tabular}{|c|c|c|c|c|c|c|c|c|c|c|c|c|}
\hline \multirow[t]{3}{*}{ Canais de Comunicação } & \multicolumn{2}{|c|}{ Extra } & \multicolumn{2}{|c|}{ Walmart } & \multicolumn{2}{|c|}{ M. Luiza } & \multicolumn{2}{|c|}{ C. Bahia } & \multicolumn{2}{|c|}{ Fnac } & \multicolumn{2}{|c|}{ F. Shop } \\
\hline & \multicolumn{12}{|c|}{ Tipo de Loja } \\
\hline & $\mathrm{F}^{\mathrm{a}}$ & $\mathrm{V}$ & $\mathrm{F}$ & $\mathrm{V}$ & $\mathrm{F}$ & $\mathrm{V}$ & $\mathrm{F}$ & $\mathrm{V}$ & $\mathrm{F}$ & $\mathrm{V}$ & $\mathrm{F}$ & V \\
\hline$e$-mail & & $\mathrm{x}$ & & $\mathrm{x}$ & & $\mathrm{x}$ & & $\mathrm{x}$ & & $\mathrm{x}$ & & $\mathrm{X}$ \\
\hline Chat/Skype & & $\mathrm{x}$ & & $\mathrm{x}$ & & $\mathrm{x}$ & & $\mathrm{X}$ & & $\mathrm{x}$ & & $\mathrm{x}$ \\
\hline Redes Sociais & & $\mathrm{x}$ & & $\mathrm{x}$ & & $\mathrm{x}$ & & $\mathrm{x}$ & & $\mathrm{x}$ & & $\mathrm{X}$ \\
\hline Central de Atendimento & $\mathrm{x}$ & $\mathrm{x}$ & $\mathrm{x}$ & $\mathrm{x}$ & $\mathrm{x}$ & $\mathrm{x}$ & $\mathrm{x}$ & $\mathrm{x}$ & $\mathrm{x}$ & $\mathrm{x}$ & $\mathrm{x}$ & $\mathrm{X}$ \\
\hline SAC & $\mathrm{x}$ & $\mathrm{x}$ & $\mathrm{x}$ & $\mathrm{x}$ & $\mathrm{x}$ & $\mathrm{x}$ & $\mathrm{x}$ & $\mathrm{x}$ & $\mathrm{x}$ & $\mathrm{x}$ & $\mathrm{x}$ & $\mathrm{X}$ \\
\hline Cartão Fidelidade & & & & & & & & & $\mathrm{x}$ & $\mathrm{x}$ & & \\
\hline Total de Serviços & 2 & 5 & 2 & 5 & 2 & 5 & 2 & 5 & 3 & 6 & 2 & 5 \\
\hline
\end{tabular}

Nota. Fonte: Elaborada pelos autores.

${ }^{a}$ As letra F e V apresentadas na tabela indicam respectivamente as palavras Física e Virtual.

No canal físico, as opções se resumem ao atendimento dado pelo SAC (Serviço de Atendimento ao Cliente) e pela central de atendimento. Varejistas que oferecem elevados níveis de qualidade dos serviços vendem significativamente mais do que aqueles com baixa qualidade (Venkatesan, Mehta, \& Ravi, 2007).

Como destaque das análises desenvolvidas sobre os componentes sortimento, preço e serviços nos canais fisico e virtual, é importante apresentar o comentário de um dos gestores entrevistados, em que são apontadas as propostas de valor de cada um dos canais.

"A proposta de valor da loja on-line pode ser resumida em: sortimento, preço, conveniência e comodidade. Da mesma forma, a proposta de valor da loja física pode ser resumida em: atendimento e compensação imediata, ou seja, levar o produto na hora da compra" (Diretor da Empresa B).

\section{Implicações Práticas e Considerações Finais}

A presente pesquisa teve, por objetivo principal, identificar e analisar as diferenças em componentes relevantes do composto de varejo - sortimento, preço, faixas de preço e serviços - entre os canais físico e virtual de empresas que operam simultaneamente os dois canais no mercado brasileiro. Os resultados alcançados podem contribuir para a melhor compreensão da diferença de atratividade dos segmentos de comércio on-line e off-line centrada nos aspectos diferenciados do mix de varejo, bem como auxiliar na formulação de estratégias de empresas que atuam no setor.

Em relação ao componente sortimento, constatou-se que as diferenças na quantidade de modelos disponíveis são significativas, sendo que, dos 756 modelos pesquisados, nas lojas virtuais foram encontrados 689 e, nas físicas, 361 modelos, ou seja, o sortimento das lojas virtuais é 91\% maior. Outra constatação importante é a de que os varejistas buscam operar com produtos cujos modelos disponíveis em cada um dos canais, na grande maioria, são diferentes, visando evitar concorrência direta entre os canais da mesma cadeia. Foram identificados somente 301 produtos comuns com repetição, tanto na loja física como na loja virtual das mesmas redes, ou seja, um percentual de $40 \%$ do total de modelos pesquisados.

De acordo com as respostas dos gestores das empresas pesquisadas, as operações são geridas separadamente como canais concorrentes, e o sortimento é considerado por eles como fundamental para 
o modelo de negócio do canal on-line, o qual está ancorado em três pilares: sortimento, preço e prazo de pagamento. Pela ênfase destacada pelos gestores, fica clara a importância dada pelas lojas on-line ao sortimento, seja ele próprio ou através do modelo de operação denominado market place, que é a utilização do site da loja on-line para a venda de produtos de outros varejistas. Conforme os depoimentos, o modelo market place é uma fonte direta de recursos para o canal on-line, através da locação de espaços no site para exposição dos produtos e pelo percentual recebido sobre a venda efetuada a partir do site.

O segundo componente da pesquisa é o preço. Para esse componente foram constatados resultados importantes, tais como uma diferença média de $-13,3 \%$ nos preços nominais a favor das lojas virtuais. Além dessa variação, quando se tratou de preços deflacionados, encontrou-se uma diferença média de $14,9 \%$, também a favor das lojas virtuais. A maioria das lojas virtuais oferece, além de preços mais baixos, como constatado na pesquisa, prazos de pagamento geralmente com planos sem juros, que podem variar de três a doze vezes. Essas diferenças foram confirmadas pelos gestores entrevistados que justificaram a estratégia, pelo objetivo das lojas on-line de se firmarem e crescerem junto ao mercado, oferecendo vantagens para o cliente, vantagens essas que podem ser consideradas como uma espécie de bônus por comprarem no canal virtual. Essa dinâmica de preços mais baixos e prazos de pagamento longos, conforme destacado pelos gestores, exige absorção de capital pela operação on-line, o que, num cenário de inflação alta, pode não se manter, por comprometer os resultados do negócio. Em mercados mais maduros, com índices de inflação baixos, a modalidade de pagamento a prazo não se aplica ao modelo on-line. Além disso, essa dinâmica de oferta de crédito, no médio prazo, pode prejudicar os resultados das lojas físicas da rede, pois estas não conseguem, na maioria das vezes, acompanhar os preços e prazos das lojas on-line e, por consequência, podem ter suas vendas e seus resultados comprometidos.

Como terceiro componente da análise, as faixas de preço têm um papel importante na relação da loja com o consumidor. $\mathrm{Na}$ análise das faixas de preço em ambos os canais, constatou-se que as lojas virtuais disponibilizam produtos em quase todas as faixas, enquanto que a maioria das lojas físicas restringe o número de faixas devido ao seu espaço físico. Com sortimento maior, as lojas virtuais disponibilizam modelos nas faixas de menor preço (faixas de entrada), nas faixas intermediárias e, principalmente, opções de produtos em faixas de preço com valores mais altos, ou seja, modelos em lançamento e, portanto, mais avançados tecnologicamente, os chamados high-ends, tática essa confirmada pelos gestores.

O quarto e último componente estudado foi o conjunto de serviços oferecidos pelos canais físico e virtual. A diferença mais significativa identificada pela pesquisa está nos meios de comunicação. As lojas on-line disponibilizam entre cinco e seis canais de comunicação para o cliente, enquanto a loja física, no máximo, disponibiliza três canais. Essa diferença a favor do canal on-line pode ser parte da estratégia dos varejistas para diminuir o impacto de falhas nos processos e minimizar o aspecto de impessoalidade da compra on-line.

Enfim, a pesquisa constatou que, para as lojas e produtos amostrados, o varejo virtual é mais competitivo do que o físico em relação ao sortimento, $91 \%$ maior, aos preços (em média de $13 \%$ a $15 \%$ menores), às condições de pagamento mais atraentes (de 3 a 12 vezes sem juros) e à amplitude de faixas de preços. Mantidos esses diferenciais competitivos e garantida a credibilidade na entrega e a possibilidade de troca ou devolução, o varejo virtual tem uma perspectiva de crescimento proporcionalmente maior do que o varejo físico, de forma consistente com o que já vem ocorrendo nos últimos anos.

Para Berman e Thelen (2004), os negócios multicanais, para terem sucesso, não podem funcionar como entidades separadas, mas devem funcionar como unidades integradas e facilitar as transações sem rupturas ou ruídos entre os diferentes canais. Assim podemos inferir que um canal não inviabiliza o outro, logo, eles podem e devem ser complementares. No entanto, as entrevistas com os gestores apresentaram um cenário das operações reais que contradiz a proposta apresentada por Berman e Thelen (2004). Conforme os comentários, as operações devem ser completamente separadas, os preços não podem ser os mesmos entre os canais, e as operações logísticas não devem ser integradas. Nessas 
contradições, podem residir as oportunidades para a realização de novos estudos que contribuam para a aproximação entre a teoria e a realidade, e que identifiquem processos operacionais, tecnologias e procedimentos de governança que permitam uma maior integração entre as operações dos canais físico e on-line de um mesmo varejista. Ainda como sugestão para estudos futuros, deve-se ampliar o número amostral de lojas e diversificar as operações varejistas com diferentes tamanhos de empresas e diferentes segmentos, assim como realizar a tomada das informações ao longo de um período maior, visando reduzir um possível impacto das variações sazonais e econômicas.

\section{Referências}

Ahmad, N., Omar, A., \& Ramayah, T. (2010). Consumer lifestyles and online shopping continuance $\begin{array}{llll}\text { intention. } & \text { Business } & \text { Strategy 227-243. }\end{array}$ http://dx.doi.org/10.1108/17515631011063767

Amit, R., \& Zott, C. (2012). Creating value through business model innovation. MIT Sloan Management Review, 53(3), 40-50. Recuperado de http://sloanreview.mit.edu/article/creating-value-throughbusiness-model-innovation/. http://dx.doi.org/10.1016/j.jbusres.2013.03.003

Barney, J. B., \& Hesterly, W. S. (2007). Administração estratégica e vantagem competitiva, conceitos e casos. São Paulo: Pearson Prentice Hall.

Berman, B., \& Thelen, S. (2004). A guide to developing and managing a well-integrated multi-channel retail strategy. International Journal of Retail and Distribution Management, 32(3), 147-156. http://dx.doi.org/10.1108/09590550410524939

Blackwell, R. D., Miniard, P. W., \& Engel, J. F. (2008). Comportamento do consumidor (9a ed. norteamericana Trad.). São Paulo: Cengage Learning. (Obra original publicada em 2001)

Bratnagar, A., \& Syam, S. S. (2013). Allocating a hybrid retailer's assortment across retail stores: bricksand-mortar vs online. Journal of Business Research, 67(6), 1293-1302. http://dx.doi.org/10.1016/j.jbusres.2013.03.003

Churchill, G. A., Jr., \& Peter, J. P. (2000). Marketing: criando valor para os clientes (C. Bartalotti; C. K. Moreira, Trad.). São Paulo: Saraiva. (Obra original publicada em 1998)

Davidson, W. R., Sweeney, D. J., \& Stampfl, R. W. (1988). Retailing management (6a ed). New York: John Wiley \& Sons.

Deloitte. (2012, January). Serving the connected consumer. The Deloitte Consumer Review, 24 p. Recuperado de http://www.luxesf.com/wp-content/uploads/2012/01/Deloitte-Serving-theconnected-consumer.pdf

E-bit - A Certificação dos Consumidores. (2014). Relatório Webshoppers (29a ed.). Recuperado de http://img.ebit.com.br/webshoppers/pdf/WebShoppers2014.pdf

Evans, P., \& Wurster, T. (2000). Explosão de bits: estratégias na e-economia. Rio de Janeiro: Campus.

Hoch, S. J., Bradlow, E. T., \& Wansink, B. (1999). The variety of an assortment. Marketing Science, 18(4), 527-46. http://dx.doi.org/10.1287/mksc.18.4.527

Jain, S. C., \& Haley, G. T. (2009). Marketing- planning and strategy. Mason: Cengage Learning.

Kopalle, P., Biswan, D., Chintagunta, P. K., Fan, J., Pauwels K., Ratchford, B. T., \& Sill, J. A. (2009). Retailer pricing and competitive effects. Journal of Retailing, 85(1), 56-70. http://dx.doi.org/10.1016/j.jretai.2008.11.005 
Kotler, P., \& Keller, K. L. (2012). Administração de marketing (14a ed., S. M. Yamamoto, Trad.). São Paulo: Pearson Education do Brasil. (Obra original publicada em 2000)

Lennon, R., \& Harris, J. (2001). Costumer service on the web: across industry investigation. Journal of Targeting Measurement and Analysis for Marketing, 10(4), 325-338. http://dx.doi.org/10.1057/palgrave.jt.5740057

Levy, M., \& Weitz, B. A. (2012). Retailing management (8a ed.). New York: Mc Graw-Hill/Irwin.

Lin, C., \& Lekhawipat, W. (2014). Factors affecting online repurchase intention. Industrial Management \& Data Systems, 114(4), 597-611. http://dx.doi.org/10.1108/IMDS-10-2013-0432

Mantrala, M. K., Levy, M., Kahn, B. E., Fox, E. J., Gaidarev, P., Dankworth, B., \& Shah, D. (2009). Why is assortment planning so difficult for retailers? A framework and research agenda. Journal of Retailing, New York, 85(1), 71-83. http://dx.doi.org/10.1016/j.jretai.2008.11

Mattar, F. N. (2011). Administração de varejo. Rio de Janeiro: Elsevier.

McGoldrick, P. J. (2002). Retail marketing (2a ed.). Berkshire, UK: Mc Graw Hill.

Melis, K., Campo, K., Breugelmans, E., \& Lamey, L. (2015). The impact of the multi-channel retail mix on online store choice: does online experience matter? Journal of Retailing, 91(2), 272-288. http://dx.doi.org/10.1016/j.jretai.2014.12.004

Morettin, P. A., \& Bussab, W. O. (2013). Estatistica básica (8a ed). São Paulo: Saraiva.

Osterwalder, A., \& Pigneur, Y. (2011). Inovação em modelos de negócios - business model generation. Rio de Janeiro: Alta Books.

Parente, J., \& Barki, E. (2014). Varejo no Brasil: gestão e estratégia (2a ed.). São Paulo: Atlas.

Porter, M. (1989). Vantagem competitiva. Rio de Janeiro: Campus.

Rao, S., Goldsby, T. J., \& Iyengar, D. (2009). The marketing and logistics efficacy of online sales channels. International Journal of Physical Distribution \& Logistics Management, 39(2), 106130. http://dx.doi.org/10.1108/09600030910942386

Rappaport, A. (2001). Gerando valor para o acionista: um guia para administradores e investidores. São Paulo: Atlas.

Reichheld, F. F., \& Schefter, P. (2000). E-loyalty: your secret weapon on the web. Harvard Business Review, 78(4), 105-113.

Rosenbloom, B. (2009). Canais de marketing: uma visão gerencial (3 reimpr.). São Paulo: Atlas.

Szymanski, D. M., \& Hise, R. T. (2000). E-satisfaction: an initial examination. Journal of Retailing, 76(3), 309-322. http://dx.doi.org/10.1016/S0022-4359(00)00035-X

Takahashi, K., Aoi, T., Hirotani, D., \& Morikawa. K. (2011). Inventory control in a two-echelon dualchannel supply chain with setup of production and delivery. International Journal. Production Economics, 133(1), 403-415. http://dx.doi.org/10.1016/j.ijpe.2010.04.019

Toledo, G. L., Proença, M. C. de A., \& Mello, S. B. de, Jr. (2006). Politica de preços e diferencial competitivo: um estudo de casos múltiplos na indústria de varejo. Revista de Administração, 4l(3), 324-338. http://dx.doi.org/10.1590/S0080-21072006000300009

Underhill, P. (1999). Vamos às compras: a ciência do consumo (I. Korytowski, Trad.). Rio de Janeiro: Campus. 
Venkatesan, R., Mehta, K., \& Ravi, B. R. (2007). Do market characteristics impact the relationship between retailer characteristics and online prices? Journal of Retailing, 83(3), 309-324. http://dx.doi.org/10.1016/j.jretai.2006.04.002

Verhoef, P. C., Neslin, S. A., \& Vroomem, B. (2007). Multichannel customer management: understanding the research - shopper phenomenon. International Journal of Research in Marketing, 24(2), 129-148. http://dx.doi.org/10.1016/j.ijresmar.2006.11.002

Yin, R. K. (2010). Estudo de caso. Planejamentos e métodos (4a ed.). Porto Alegre: Bookman.

\section{Dados dos Autores}

Mário Duarte dos Santos Machado

Rua Santo Antonio, 50, 09521-160, São Paulo, SP, Brasil. E-mail: mario.du.machado@ hotmail.com

Sergio Feliciano Crispim

Rua Santo Antonio, 50, 09521-160, São Paulo, SP, Brasil. E-mail: scrispim@uol.com.br 


\section{APÊNDICE A}

\section{Atributos de Lojas Físicas e Virtuais Destacados por Diversos Autores}

\begin{tabular}{lll}
\hline Autores & Atributos Lojas On-Line & Atributos Lojas Físicas \\
\hline $\begin{array}{l}\text { Reichheld e Schefter } \\
(2000)\end{array}$ & Variedade e rapidez na compra. & $\begin{array}{l}\text { Localização, conveniência, } \\
\text { atendimento. }\end{array}$ \\
\hline $\begin{array}{l}\text { Deloitte (2012); Toledo } \\
\text { et al. (2006) }\end{array}$ & $\begin{array}{l}\text { Convergência tecnológica, acesso a informações, facilidade } \\
\text { de realizar escolhas, combinação de diferentes dispositivos } \\
\text { eletrônicos, facilidade em organizar o recebimento do } \\
\text { produto, conectividade e interatividade. }\end{array}$ & \\
\hline $\begin{array}{l}\text { Ahmad, Azisah e } \\
\text { Ramayah (2010) }\end{array}$ & $\begin{array}{l}\text { Informações ilimitadas sobre produtos e serviços, } \\
\text { comparação instantânea de preços e custos através de } \\
\text { ferramentas de pesquisa, liberdade de mudança de } \\
\text { fornecedor ou do local onde realiza a compra, serviços 24 } \\
\text { horas por dia. }\end{array}$ & \\
\hline Takahashi et al. (2011) & $\begin{array}{l}\text { Busca de informações e comparações de preços entre } \\
\text { produtos, varejistas e canais. }\end{array}$ & $\begin{array}{l}\text { Facilidade de negocição com } \\
\text { as equipes de vendas. }\end{array}$ \\
\hline Rosenbloom (2009) & $\begin{array}{l}\text { Alcance global, conveniência, processamento rápido das } \\
\text { informações, eficiência e flexibilidade no processamento de } \\
\text { informações, gestão baseada em dados, grande capacidade } \\
\text { de relacionamento, menores custos de venda e distribuição. }\end{array}$ & $\begin{array}{l}\text { Atmosfera de compra, } \\
\text { produto }\end{array}$ \\
\hline
\end{tabular}

Levy e Weitz (2012, p. “Segurança, conveniência, amplo e profundo sortimento, 61) compartilhamento de informações com outros clientes sobre produtos e/ou serviços, informações em curto espaço de tempo. Elimina a necessidade de deslocamento até a loja".

Verhoef et al. (2007) Conveniência de pesquisa, informações para comparação, menor esforço de compra, tempo na compra, preço e promoção.

Tocar e sentir os produtos, serviço, privacidade, negociação, gratificação imediata, entretenimento e interação social, pagamento na hora, pós-venda.

\begin{tabular}{|c|c|c|}
\hline Underhill (1999) & $\begin{array}{l}\text { Seleção ilimitada, compras a qualquer hora do dia ou da } \\
\text { noite. }\end{array}$ & \\
\hline $\begin{array}{l}\text { Szymanski e Hise } \\
(2000)\end{array}$ & $\begin{array}{l}\text { Conveniência, opções de produtos oferecidos, informações, } \\
\text { facilidade de navegação, design do site, segurança para as } \\
\text { transações financeiras e pontualidade na entrega. }\end{array}$ & \\
\hline $\begin{array}{l}\text { Blackwell, Miniard e } \\
\text { Engel }(2001 / 2008)\end{array}$ & $\begin{array}{l}\text { Realçar a imagem, atingir consumidores onde não haja } \\
\text { atuação física da empresa, fornecer e obter informações, } \\
\text { promover produtos e serviços de maneira integrada com } \\
\text { fornecedores, ofertar produtos e serviços diferenciados de } \\
\text { forma dirigida, obter feedback do cliente. }\end{array}$ & \\
\hline E-bit (2014) & $\begin{array}{l}\text { Oferta de produtos para nichos de mercado e opção de } \\
\text { escolha. }\end{array}$ & \\
\hline $\begin{array}{l}\text { Newman (2007 como } \\
\text { citado em Kotler \& } \\
\text { Keller, 2000/2012, p. } \\
486)\end{array}$ & & $\begin{array}{l}\text { "Vivenciar experiências que } \\
\text { ativam e cativam os sentidos, } \\
\text { vivenciar aspectos físicos da } \\
\text { loja, atributos relacionados } \\
\text { diretamente aos produtos, } \\
\text { interação pessoal com os } \\
\text { clientes". }\end{array}$ \\
\hline
\end{tabular}




\section{APÊNDICE B}

\section{Temas, Questões e Convergência das Respostas das Entrevistas Semiestruturadas, com Base nos Blocos Típicos dos Modelos de Negócio}

\begin{tabular}{lll}
\hline Temas & Questões & Convergência das Respostas \\
\hline Canais & $\begin{array}{l}\text { Com a criação do canal on-line, houve a } \\
\text { necessidade de criação /separação de áreas, } \\
\text { departamentos ou unidades de negócios? }\end{array}$ & $\begin{array}{l}\text { As operações são diferentes e as equipes são } \\
\text { segregadas. }\end{array}$
\end{tabular}

Como é a gestão de cada um dos canais?

Em algum momento, os canais físico e virtual se integram? Como?

\begin{tabular}{ll}
\hline Proposta de & Qual é a proposta de valor, conjunto de \\
Valor & produtos e serviços, oferecidos aos clientes?
\end{tabular}

Qual dos canais apresenta o melhor custo benefício para o cliente? E para a empresa?

Os clientes estão dispostos a pagar pelos valores entregues em cada um dos canais?

Atividadeschave

Para entregar a proposta de valor de cada canal, quais atividades-chave são requeridas?

Os parceiros (fornecedores de produtos e serviços) participam das atividades-chave?

Segmentos de Quem são os clientes mais importantes? Clientes

Na sua percepção, as necessidades de cada um desses clientes estão sendo atendidas?

Relacion. com O que mudou no relacionamento com os

Clientes
Três operações são independentes; as demais são integradas.

A integração esbarra em aspectos de governança, tais como investimento, custos, despesas e receitas, mas já há algumas iniciativas integradas.

Loja física: atendimento e experiência de compra. Loja virtual: conveniência, comodidade, sortimento, preço e condições de pagamento.

Para o cliente, na loja on-line, as variáveis comodidade, preço e condições de pagamento tendem a ser mais interessantes.

Sim, pois cada um dos canais entrega valores diferentes conforme a necessidade de consumo do cliente, em cada momento.

Canal on-line: tecnologia da informação adequada, sortimento, operação logística eficiente e processo de precificação dinâmico. Canal físico: tecnologia da informação adequada, sortimento, treinamento e motivação das equipes de vendas.

Sim: logística, SAC, exposição e divulgação eletrônica de produtos.

Clientes de programas de fidelidade e de segmentos específicos de maior retorno.

Ainda há espaço para melhorias no atendimento às necessidades dos clientes.

Gestão mais eficaz das informações, atendimento da necessidade do cliente, independente da sua localização física e individualização das ofertas.

Como os clientes percebem e geram feedback São disponibilizados diversos meios on-line sobre as operações do canal virtual? para receber feedback. Esses canais indicam boas percepções do cliente quanto ao canal on-line.

Como os clientes percebem e geram feedback O meio mais utilizado na loja física para sobre as operações do canal físico? receber feedback é direto na loja, junto ao SAC ou aos funcionários.

Em ambos os canais, fornecedores de produtos, Sellers (outros varejistas que

\begin{tabular}{lll}
\hline Parcerias & Quais são os principais parceiros nas & Em ambos os canais, fornecedores de \\
Principais & operações de cada canal? & produtos, Sellers (outros varejistas que
\end{tabular}




\begin{tabular}{|c|c|c|}
\hline & & $\begin{array}{l}\text { compartilham vendas no site da loja), } \\
\text { operadores logísticos, fornecedores de } \\
\text { soluções em gestão da informação, } \\
\text { comunicação e marketing. }\end{array}$ \\
\hline & $\begin{array}{l}\text { Os parceiros executam alguma das atividades- } \\
\text { chave nas operações de cada canal? }\end{array}$ & $\begin{array}{l}\text { Sim. Operações logísticas, gestão da } \\
\text { tecnologia da informação e mídias digitais. }\end{array}$ \\
\hline \multirow[t]{5}{*}{$\begin{array}{l}\text { Recursos } \\
\text { Principais }\end{array}$} & $\begin{array}{l}\text { O canal on-line exige novas especializações / } \\
\text { capacitações dos colaboradores? }\end{array}$ & $\begin{array}{l}\text { Especialização no segmento, visão de } \\
\text { processos, visão multicanal e capacidade } \\
\text { analítica para gestão de grandes volumes de } \\
\text { informações. }\end{array}$ \\
\hline & $\begin{array}{l}\text { Como são suportadas, nos aspectos logísticos, } \\
\text { as operações de cada um dos canais? }\end{array}$ & $\begin{array}{l}\text { As operações on-line são suportadas na } \\
\text { maioria por Centros de Distribuição } \\
\text { independentes dos Centros de Distribuição } \\
\text { das lojas físicas. As especialidades exigidas } \\
\text { dos operadores logísticos são diferentes em } \\
\text { cada canal. }\end{array}$ \\
\hline & $\begin{array}{l}\text { Como são suportadas, no aspecto financeiro, } \\
\text { as operações de cada um dos canais? }\end{array}$ & $\begin{array}{l}\text { No canal on-line, há a exigência de capital } \\
\text { para financiar as operações de crédito, com } \\
\text { prazos que variam de } 5 \text { a } 12 \text { vezes sem juros. } \\
\text { A loja física opera com fluxo positivo. }\end{array}$ \\
\hline & $\begin{array}{l}\text { As tecnologias que suportam a gestão de cada } \\
\text { um dos canais são integradas? }\end{array}$ & $\begin{array}{l}\text { As estruturas de TI são independentes, com } \\
\text { alguma integração. }\end{array}$ \\
\hline & $\begin{array}{l}\text { O pacote tecnológico está atualizado e } \\
\text { adequado às demandas de cada canal? }\end{array}$ & $\begin{array}{l}\text { Os pacotes tecnológicos tendem a estar } \\
\text { atualizados e adequados às demandas de } \\
\text { ambos. }\end{array}$ \\
\hline
\end{tabular}

\begin{tabular}{ll}
\hline Estrutura de & Quais são os custos mais importantes em cada \\
Custos & um dos canais?
\end{tabular}

Quais atividades-chave são mais caras? Canal on-line: logística. Canal físico:

Canal on-line: fretes, custo de capital, depreciação da tecnologia e massa salarial. Canal físico: estoques, massa salarial, depreciação da tecnologia e marketing. operação.

Que recursos principais são mais caros?

Em ambos os canais: mão de obra.

\begin{tabular}{ll}
\hline Fonte de & Qual a participação / contribuição de cada \\
Receita & canal para o total da receita?
\end{tabular}

Segundo um dos varejistas, a loja on-line corresponde a $10 \%$ de todo o varejo da empresa. Em termos gerais, no Brasil, o varejo on-line está entre 3\% e $4 \%$ do total.

As contribuições de cada canal são tratadas de Para a maioria dos varejistas, as contribuições forma independente ou integrada? são tratadas separadamente.

Um canal subsidia ou pode subsidiar o outro? Para a maioria dos varejistas, não há subsídio entre os canais.

Visão de Futuro Como você vê o futuro da loja física?

O canal físico integrado com o mundo digital e exercendo um papel de formador de opinião e gerador de experiências.

Quais são os grandes desafios da operação integrada entre os dois canais?

A Governança entre os canais, os aspectos tributários e fiscais.

$\mathrm{Na}$ sua visão, quais as perspectivas para o negócio da empresa e do setor de varejo?

Integração entre os canais e multiformatos são os caminhos para atender às necessidades do cliente e para as empresas de varejo se perpetuarem. 